

\title{
APRENDIZAGEM INTEGRADORA NO PERCURSO FORMATIVO DO AMBIENTE ESCOLAR
}

\author{
Barbara Luiza da Silva da Depin ${ }^{1}$ \\ Lucas Vitor Baumgärtner² \\ Recebido em: \\ Aceito em:
}

RESUMO: O presente trabalho tem como objetivo relatar a experiência dos alunos em processo de formação à docência pela Universidade Regional de Blumenau (FURB) e bolsistas do Programa de Educação Superior para o Desenvolvimento Regional (PROESDE) durante a elaboração de um plano de aula interdisciplinar, atividade proposta como trabalho de conclusão da extensão universitária. Com o apoio da Base Nacional Comum Curricular do Ensino Médio (BNCC, 2018) e a partir de aulas sobre a teoria histórico-cultural de Vigotski e do ensino desenvolvimental de Davidov, os estudantes foram orientados a elaborar um plano de aula interdisciplinar da área das linguagens e suas tecnologias (BNCC, 2018) para o Ensino Médio. As ações mentais foram idealizadas e organizadas por Davidov (2013/1986), considerando-se quatro categorias para que a prática educativa envolva a atividade de estudo e relacione-se com a constituição do pensamento teórico do aluno, sendo estas: a) os amplificadores culturais e ação mediada; b) grau de abstração e relações de generalidade; c) participação orientada e d) emergência de espaços comunicativos. O grupo trabalhou com o componente curricular linguagens (artes visuais e teatro), buscando complexificar a criticidade e sensibilidade para com a arte a medida em que os passos mentais avançam, estimulando os alunos a explorarem o mundo artístico e terem a arte como algo essencial no seu cotidiano. Todo o processo de produção do planejamento se deu de forma remota, com auxílio e intervenção do tutor do programa de extensão.

Palavras-chave: Novo Ensino Médio. Planejamento integrado. Ensino Desenvolvimental. Teoria Histórico-cultural.

\section{INTEGRATING LEARNING IN THE FORMATIVE COURSE OF THE SCHOOL ENVIRONMENT}

ABSTRACT: This paper aims to report the experience of students in the process of training for teaching at the Regional University of Blumenau (FURB) and scholarship holders of the Higher Education Program for Regional Development (PROESDE) during the preparation of an interdisciplinary lesson plan, activity proposed as the completion of the university extension work. With the support of the National Common Curriculum Base for High School (BNCC, 2018) and from

1 Cursando a 8 fase do curso de Pedagogia da Fundação Universidade Regional de Blumenau. Fundação Universidade Regional de Blumenau. ORCID: https://orcid.org/0000-0001-7744-0635. bdepin@furb.br.

${ }^{2}$ Mestre em Educação pela Fundação Universidade Regional de Blumenau. Fundação Universidade Regional de Blumenau. ORCID: https://orcid.org/0000-0001-9888-530X. lucasvbaumgartner@gmail.com. 
classes on Vygotski's historical-cultural theory and Davidov's developmental teaching, students were guided to prepare an interdisciplinary lesson plan in the area of languages and their technologies (BNCC, 2018) for high school. Mental actions were idealized and organized by Davidov (2013/1986), considering four categories so that the educational practice involves the study activity and is related to the constitution of the student's theoretical thought, namely: a) the amplifiers cultural and mediated action; b) degree of abstraction and generality relations; c) guided participation and d) emergence of communicative spaces. The group worked with the language curriculum component (visual arts and theater), seeking to make the criticality and sensitivity to art more complex as the mental steps advance, encouraging students to explore the artistic world and have art as something essential in the your daily life. The entire planning production process took place remotely, with the assistance and intervention of the extension program tutor.

Keywords: New High School. Integrated planning. Developmental Teaching. Historical-cultural theory.

\section{INTRODUÇÃO}

O presente relato de experiência tem como objetivo elucidar o trajeto do novo Ensino Médio a partir da Base Nacional Comum Curricular do novo Ensino Médio (2019), por licenciados da área de Linguagens (Artes, Teatro, Pedagogia e Letras) no Programa de Educação Superior para o Desenvolvimento Regional - PROESDE Licenciatura da Universidade Regional de Blumenau.

O PROESDE é um curso de extensão ofertado para as licenciaturas (formação de professores), possibilitando uma bolsa de estudos na qual os acadêmicos recebem créditos financeiros em troca de horas dedicadas ao curso.

Por conta da pandemia da covid-1933, a solução para as aulas aconteceu de forma remota, de forma quinzenal, aos sábados, com atividade de formação sobre o novo ensino médio e com exercícios específicos para fomentar discussões sobre a nova formatação do ensino médio. Foi explorado o contexto histórico, as legislações e documentos que amparam a educação brasileira e estadual. Com base nesses documentos, ocorreram provocações e discussões que auxiliaram os bolsistas a compreenderem esse processo de mudança e atualização do Novo Ensino Médio.

Primeiramente foi exposto as faces do professorado; conhecemos as resoluções que regem o ensino médio, os itinerários e como funcionam; a teoria histórico-cultural de Vygotsky; a pesquisa com a perspectiva do Nóvoa (2009);

\footnotetext{
${ }^{3}$ Umas das principais formas de evitar a proliferação do vírus da COVID-19 foi o distanciamento social. Com isso, as aulas presenciais foram cancelas. De forma remota, o ensino continuou.
} 
exploramos o Ensino Desenvolvimental de Vygotsky, Devydol e Leontiev para a elaboração de planejamentos integrados.

Entre as atividades realizadas, desenvolvemos um vídeo propaganda, com o intuito de informar os leigos sobre a nova matriz curricular do Novo Ensino Médio. Elaboramos um mapa conceitual baseado na BNCC (2019), selecionando uma linguagem e uma competência para criar conteúdo respectivos a essas linguagens. Construímos um itinerário para a área de linguagens com o tema de sustentabilidade. Redigimos um caso de ensino com uma problemática e possível solução. Escrevemos um diário reflexivo para refletir sobre a importância de se ensinar por áreas de conhecimentos e um quadro sinóptico sobre os conteúdos da área de linguagens. Confeccionamos uma imagem para interpretar o texto do Nóvoa (2005): "A carta para um jovem investigador". Refletimos sobre a elaboração de relatos de experiências de professores do ensino médio para a iniciação da nossa pesquisa. O planejamento integrado entre as áreas de artes e teatro foi sendo reelaborado ao decorrer do curso.

\section{DESENVOLVIMENTO}

Este estudo qualifica-se como pesquisa qualitativa por procurar responder ao como, o micro processo do problema estudado, a partir de nuances não deslumbradas em pesquisas quantitativas.

De caráter exploratório, pois buscamos conhecer, aprofundar e explanar todos os dados gerados a partir dos instrumentos de pesquisa.

Por meio de uma pesquisa de campo. A pesquisa de campo consiste em uma ferramenta fundamental, onde, aproxima o pesquisador/ autor com o campo do estudo (problema de pesquisa). Segundo Trujillo e Ferrari (1982, p. 229), não podemos confundir como uma simples geração de dados "[...] é algo mais que isso, pois exige contar com controles adequados e com objetivos preestabelecidos que discriminam suficientemente o que deve ser coletado".

Portanto, buscamos desenvolver hipóteses de como tem se ensinado em período pandêmico, bem como verificar as perspectivas do Novo Ensino Médio na escola.

Como instrumentos de pesquisa, utilizamos o questionário aberto (elaborados pela plataforma Google Forms), aplicados duas vezes, com o intuito de obter o 
controle ${ }^{4}$ sobre o preenchimento do questionário e os dados gerados. Há também algumas vantagens que o questionário eletrônico favorece, como nos diz Vasconcellos-Guedes e Guedes (2007, p. 07), "o questionário eletrônico possibilita um aumento na velocidade de apuração dos dados coletados. [...] O questionário eletrônico é programado de modo que a tabulação seja automática".

A população são os professores da Escola Estadual Ensino Básico Adolpho Konder. A amostra são apenas os professores das disciplinas de Arte, Língua Portuguesa, Língua Inglesa e Educação Física.

\section{O CONTEXTO}

A pesquisa realizou-se com oito professores da área das linguagens e suas tecnologias, abrangendo as disciplinas de Artes, Língua portuguesa, Língua Inglesa e Educação física da Escola Estadual Básica Adolpho Konder com o objetivo de evidenciar a adaptação ao ensino mediado por tecnologia em período pandêmico e a capacitação para lidar com esse novo formato de ensino. A escola, localizada no bairro da Velha, em Blumenau, oferece aulas para o ensino fundamental e médio, não sendo escola piloto na implementação do Novo Ensino Médio

O primeiro questionário foi elaborado em conjunto ao grande grupo a partir da análise de relatos de experiência sobre práticas diversas, abrangendo o contexto e reflexões de ensino. Portanto, será abordado a formação e práticas, bem como a perspectiva da nova proposta educacional de professores da área de linguagens e suas tecnologias da escola e experiências de ensino. Com o segundo questionário, indagou-se sobre práticas educacionais em período pandêmico.

A comunicação com os professores dos componentes curriculares de Arte, Língua Portuguesa, Língua Inglesa, Teatro e Educação Física se deu por intermédio da diretora da escola, que enviou o link para os questionários e carta de apresentação da pesquisa.

\section{O TEMA E PERCURSO}

\footnotetext{
${ }^{4}$ Pois, a plataforma permite exigir do respondente que algumas questões não sejam deixadas em branco, por exemplo.
} 
O primeiro questionário sucedeu-se através da plataforma GoogleForms, tendo o objetivo de: 1) conhecer o contexto do âmbito escolar da EEB Adolpho Konder; 2) verificar o perfil profissional dos docentes, se têm conhecimento da BNCC ou da Proposta Curricular Catarinense e da proposta do Novo Ensino Médio; 3) conhecer as práticas educativas dos professores; 4) observar se há interdisciplinaridade nos planejamentos; 5) quais os recursos, materiais e plataformas são utilizados nas aulas; 6) verificar a aprendizagem durante a pandemia e as dificuldades que os docentes enfrentam para ministrar suas aulas de forma remota.

Nossa pesquisa alcançou uma amostra de oito professores da área de conhecimento de linguagens e suas tecnologias do novo Ensino Médio, dos componentes curriculares de educação física (25\%), língua portuguesa $(12,5 \%)$, língua inglesa (25\%), língua portuguesa/língua inglesa (25\%) e artes visuais (12,5\%). A média de idade dos professores é de 38 anos, sendo $75 \%$ mulheres e $25 \%$ homens. A média de tempo de atuação na escola é de 22 anos, firmando a experiência na docência dos professores.

O documento da Base Nacional Comum Curricular tem como papel fundamental:

[...] superar a fragmentação das políticas educacionais, enseje 0 fortalecimento do regime de colaboração entre as três esferas de governo e seja balizadora da qualidade da educação. Assim, para além da garantia de acesso e permanência na escola, é necessário que sistemas, redes e escolas garantam um patamar comum de aprendizagens a todos os estudantes (BRASIL, 2019, p. 08).

É essencial que os educadores dominem este documento como base para suas aulas. No entanto, com a aplicação do questionário constatamos que somente $37,5 \%$ têm pleno conhecimento e $62,5 \%$ possuem razoavelmente o conhecimento sobre tal documento, evidenciando a falta de interesse e compromisso para com a continuidade de formação. Segundo Evangelista e Seki (2017), as rupturas encontradas nas salas de aula são o excesso de trabalho e a falta de reconhecimento pelas políticas públicas.

A Proposta Curricular Catarinense tem o intuito de propor uma formação humana integral e construir um percurso formativo para buscar a ampliação e compreensão do mundo, de seus conhecimentos e saberes (SANTA CATARINA, 2014). Com isso, salienta-se a importância do desenvolvimento de planejamentos integrados para que haja uma integração de conhecimentos das áreas. 
Indagou-se aos professores se possuem conhecimento sobre a Proposta Curricular de Santa Catarina. 12,5\% dizem ter pleno conhecimento, enquanto 87,5\% alegam ter conhecimento razoável. Elucida-se, portanto, a escassez de práticas integradoras em sala de aula.

O Novo Ensino Médio surgiu para romper com o ensino tradicional, colocando o estudante como protagonista em seus estudos e escolhas. Perante o Caderno de Orientações Para a Implementação do Novo Ensino Médio:

[...] o Novo Ensino Médio veio para atender as necessidades e anseios da juventude, que deve ser estimulada a aprofundar as aprendizagens pela escuta de seus interesses. É prioridade incentivar ao jovem a desenvolver o protagonismo, a autonomia e a responsabilidade por suas escolhas, a partir da garantia de aprendizagens comuns a todos e da oferta de itinerários formativos. Nessa nova configuração, os conhecimentos serão atravessados por eixos de ação que trazem sentido ao fazer pedagógico, que deve perpassar pelos caminhos contextualizados e organizados por Áreas do Conhecimento. A partir desses eixos, o estudante poderá realizar investigações científicas, desenvolver sua capacidade de produção criativa, mediar e intervir sócio-culturalmente no meio em que se encontra inserido e, ainda, desenvolver sua capacidade empreendedora (SANTA CATARINA, 2019, p. 11).

Contudo, percebe-se que os educadores ainda não estão por dentro desta implementação do Novo Ensino Médio, conforme os dados do gráfico a seguir:

\section{Gráfico 1 - Conhecimento a respeito da proposta do Novo Ensino Médio}

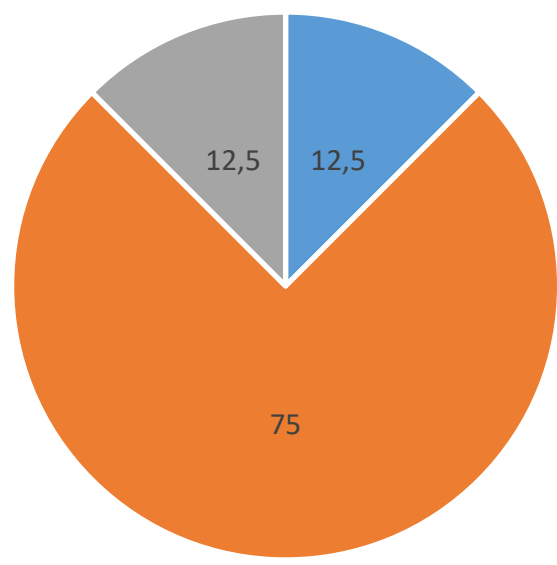

- Bastante $\quad$ Razoável Nada

Fonte: os autores (2021).

Portanto, $85 \%$ dos professores que possuem algum conhecimento sobre a proposta do Novo Ensino Médio dizem ter se informado na escola, enquanto 14\% tiveram abordagem sobre o tema durante a graduação. A partir destes resultados, fazse um paralelo com as práticas educativas mediadas por tecnologia no atual período 
pandêmico.

Não ocorreu nenhuma observação sobre as propostas dos professores da escola Adolpho Konder, pois nenhum docente tinha disponibilidade em nos atender, devido a situação de pandemia e por estar sobrecarregado por conta das aulas remotas. Por tanto a pesquisa ficou submetida apenas no questionário que os docentes responderam, e a partir destes dados refletimos sobre o percurso formativo do ambiente escolar.

A partir dos dados obtidos sobre o conhecimento que os docentes têm pelo novo ensino médio e da proposta curricular catarinense, constatou-se a necessidade da realização de formação continuada e da troca de informações entre universidade e escolas, no intuito de que as teorias sejam compartilhadas e utilizadas para repensar a didática.

\section{RELATO DA PRÁTICA}

A Escola de Educação Básica Miguel Couto não faz parte das escolas denominadas piloto do NEM (Novo Ensino Médio), mas segundo relato de uma das professoras participantes da pesquisa, a partir de 2021, a escola passará a fazer parte dessa relação de implementação da política do Novo Ensino Médio. Mesmo com a pandemia, a instituição de ensino foi orientada pela Secretaria de Educação do Estado a promover ações para os professores já irem conhecendo o que está sendo aperfeiçoado na modalidade de ensino. Os professores foram convidados pela escola para planejarem aulas trazendo as propostas do Novo Ensino Médio.

A Secretaria promoveu uma formação entre os dias 3 e 5 de fevereiro de 2020 aos gestores da escola, com isso a instituição tinha autonomia para orientar seus professores. Conforme relato, teve professores que recusaram participar do projeto, por motivos não mencionados pela docente entrevistada. Alguns professores aceitaram o convite, inclusive a professora de Língua Portuguesa Leuzicléia Duarte que fez parte da pesquisa respondendo o questionário e apresentou para o grupo uma de suas propostas que teve como objetivo desenvolver o protagonismo dos estudantes.

O plano seguiu o cronograma das aulas mediadas por tecnologia onde os estudantes e a professora se reuniram na plataforma Hangout Meet. Foram necessárias 10 aulas para a conclusão da proposta que ocorreram do dia 31 de agosto 
a 09 de setembro de 2020 e a turma onde foi aplicado o planejamento foi o $1^{\text {a }}$ ano do Ensino Médio, contando com 40 estudantes. O tema escolhido pela professora foi "A importância e a influência das pessoas na sua vida", baseando-se na BNCC a educadora escolheu os objetivos, habilidades e competências para fundamentar às aulas. Os principais objetivos esperados foram promover o autoconhecimento, reconhecer a importância da família; perceber que o meio em que você vive pode influenciar nas suas escolhas; verificar se houve compreensão dos temas propostos e dos pontos de vista expostos; vivenciar uma atividade diferenciada e inspiradora a fim de elevar seus horizontes para opções na vida. As aulas foram divididas em 10 momentos: $1^{\circ}$ momento, roda de conversa; $2^{\circ}$ momento, assistir ao filme "Escritores da Liberdade"; $3^{\circ}$ momento, trazer uma profissional da psicologia para falar com os alunos sobre a importância da família da escola na sua vida dos estudantes; $4^{\circ}$ momento, tarefa de casa; $5^{\circ}$ momento, socializar Mentimeter; 6o momento, apresentação de jogral; $7^{\circ}$ momento, eu e a minha vida pessoal; $8^{\circ}$ momento, tarefa de casa; $10^{\circ}$ momento, roda de conversa final com a condução dos alunos.

Para o $1^{\circ}$ momento foi proposto uma roda de conversa que serviu para estimular os estudantes a uma reflexão do momento atual, fazendo-os refletirem sobre o papel de cada um em sua família, com as experiências escolares. Além disso, despertar sentimento de pertencimento a um grupo, bem como desenvolver 0 protagonismo juvenil, ou seja, fazer com que os estudantes percebam a importância da sua participação na tomada de decisões pessoais e profissionais; desenvolver o autoconhecimento. No $2^{\circ}$ momento a professora propôs que os alunos assistissem ao filme "Escritores da Liberdade", tendo como objetivo que desenvolvessem uma reflexão crítica, mostrando-os que cada indivíduo tem um potencial, basta oportunidades para que isso seja exposto e alguém que the passe segurança e motivação. No $3^{\circ}$ momento, a proposta feita para os alunos foi trazer um palestrante para conversar sobre a importância da família na vida dos estudantes, se existe diferença na vida do estudante que têm os pais presentes na vida dele e se à ausência deles pode influenciá-lo de forma negativa. Os alunos teriam que formular uma pergunta para fazer para o/a palestrante. No $4^{\circ}$ momento, foi proposto como tarefa de casa que os alunos escrevessem em uma folha ou cartaz uma frase para eles mesmos ou um amigo. O principal objetivo da professora com essa prática era que os alunos fossem capazes de serem escritores da sua história. Nessa folha ou cartaz deveria conter uma frase legível e sem ferir os direitos humanos. No $5^{\circ}$ momento, os 
estudantes socializaram pelo Mentimeter e apresentaram a tarefa de casa dada na aula anterior.

Ao final da aula, também ficou como tarefa para pesquisar algum texto, poesia ou música relacionada ao tema "semana da pátria" e na aula seguinte fazer uma apresentação. A atividade proposta foi apresentada em forma de jogral, fazendo parte do 6o momento, onde foram avaliados critérios como, criatividade, sincronia, fluência e pronúncia, entonação da voz, respeitando os sinais de pontuação e principalmente o compromisso e a seriedade com o trabalho. Já no $7^{\circ}$ momento através do Google Meet, inicia-se uma discussão a respeito da vida escolar, os professores ficam encarregado de trazer provocações como, qual é a lembrança mais antiga que você tem da vivência na escola? Onde foi? Quando foi? Quem mais estava lá? Qual professor marcou mais sua vida de forma positiva? pedindo para que os alunos descrevam como foi a influência desse professor em sua vida. "Você passou por quais instituições de ensino? O que aprendeu de mais marcante em cada uma delas?"; sua forma preferida de aprender: escutando o professor, lendo livros e textos, estudando com colegas; você costuma estudar sozinho? Se sim, quantas vezes por semana, geralmente? Como é seu jeito de participar das aulas? Prefere participar bastante, fazer perguntas ao professor, dar suas opiniões ou prestar atenção e anotar o que 0 professor fala? No $8^{\circ}, 9^{\circ}$ e $10^{\circ}$ momento os alunos conduziram uma roda de conversa final, onde comentaram sobre o que foi debatido na primeira roda de conversa e quais foram os aprendizados adquiridos com a palestra da profissional no $3^{\circ}$ momento, e por fim, sobre o filme assistido "Escritores da Liberdade". Com tudo, devem ver entre eles se houve mudança no pensamento de cada um, como avaliar essa semana que se passou, e o que mais chamou a atenção deles na mesma. Os critérios avaliados foram da participação efetiva, serenidade e compromisso.

\section{APORTES TEÓRICOS NECESSÁRIOS PARA REFLEXÃO DO EXPERIENCIADO}

O aporte teórico principal dos questionários e do desenvolvimento deste trabalho é a Base Nacional Comum Curricular (2019), pelo fato de guiar todo o currículo do novo Ensino Médio. As aprendizagens que a BNCC propõe aos estudantes no âmbito pedagógico, os direitos de aprendizagem e desenvolvimento, são definidas por meio de competências. Defina-se por competência:

[...] como a mobilização de conhecimentos (conceitos e procedimentos), habilidades (práticas, cognitivas e socioemocionais), atitudes e valores para 
resolver demandas complexas da vida cotidiana, do pleno exercício da cidadania e do mundo do trabalho (BRASIL, 2019, p. 8).

Com essas competências, a BNCC tem o objetivo de alcançar diferentes contextos e particularidades dos estudantes do Ensino Médio.

É proposto pelas diretrizes que se faça um planejamento apoiado em um percurso formativo, a partir de um movimento contínuo de aprendizagens que segundo a Proposta Curricular de Santa Catarina $(2019$, p. 8) "[...] deve prevalecer a ideia de complexificação, objetivando o repertório dos conhecimentos inerentes". Ou seja, selecionar objetos de conhecimento considerando a realidade de cada turma e escola.

A BNCC é "orientada pelos princípios éticos, políticos e estéticos que visam à formação humana integral e a construção de uma sociedade justa, democrática e inclusiva" (BRASIL, p. 7). Em 2007 o termo "formação integral" foi instituído como meta do Plano de Desenvolvimento da Educação (PDE) que visava a equidade nas oportunidades educacionais, caracterizando-o por uma carga horária ampliada como estratégia de ampliação e consolidação do direito educativo.

\footnotetext{
Mais tempo educativo na escola (ou sob sua supervisão) para a ampliação dos horizontes formativos, das experiências educativas, de abordagens culturais, estéticas, esportivas, comunicacionais, científicas, corporais, a serem recuperados em um processo de ressignificação das práticas escolares (MOLL, 2014, p. 374).
}

Portanto, a formação integral é atrelada à uma conexão entre escola e estudantes, tendo o estudante como protagonista e construtores da própria trajetória educativa significativa, projeto de vida e sociedade.

Compreende-se por percurso formativo o processo constitutivo e constituinte da formação humana. Perante os autores Nuñes e Ramalho (2002) esse percurso deve propiciar novas experiências, de aprender a aprender e de fazer com que haja reflexão sobre suas práticas. Nesse mesmo sentido elaboram os itinerários formativos.

Os itinerários formativos em Santa Catarina compreendem três principais eixos para a formação básica e flexível do currículo para articular em uma única proposta pedagógica, são elas: a) Projeto de vida; b) Trilhas de aprofundamento, envolvendo as áreas de conhecimento e/ou formação técnica e profissional; c) Componentes Curriculares Eletivos (2019, p. 15).

O profissional que irá trabalhar com essa nova proposta precisa se reconhecer 
como um novo aprendiz, pois para os autores Evangelista e Seki (2017), o professor aprendiz tem que saber fazer o aluno aprendiz, sem a mediação do ensino. E é essa a nova proposta do Ensino médio, é fazer com que o aluno e o professor se desprendem das disciplinas/conteúdo, e partem para uma formação integradora resultando em alunos e profissionais pensantes e atores sociais.

\section{RESULTADOS}

A escola não é piloto na implementação do Novo Ensino Médio, assim como também não há evidências de implantação dele. Com base nos resultados do questionário, percebe-se uma grande escassez de conhecimento referente às novas diretrizes do Novo Ensino Médio, que veio com o princípio de

[...] dialogar com as exigências de uma nova sociedade, gerado no âmbito das transformações tecnológicas, econômicas, das novas formas de produção do conhecimento; da globalização, não só das econômicas, como também do conhecimento (NUÑEZ; RAMALHO, 2002, p. 1).

Podemos compreender que os professores estão presos nas antigas diretrizes do Ensino médio, mas nota-se que há alguns que buscam por diferentes propostas pedagógicas, contemplando algumas concepções da nova proposta. Um fator que poderia mudar essa adversidade, seria implantar formações e reuniões continuadas para que os professores conheçam e estudem as novas diretrizes. Os autores Nuñes e Ramalho (2002, p. 04) ressaltam a importância dessa formação: "Uma formação de professores sem direção e sem conhecimento das suas necessidades reais, não se ajusta às mudanças, que exigem cada vez mais uma ação criadora na preparação dos professores na perspectiva da profissionalização"

Diante disso, percebemos como o percurso do PROESDE é de suma importância para uma formação de docentes, pois todas as propostas e vivências são pensadas em formar um professor de qualidade e que nunca deixe de buscar pelo novo. Possibilitando uma experiência rica e que modifique o jeito de ser do docente, buscando por novas metodologias para suas aulas, com o objetivo de formar alunos pensantes e cidadões.

As instituições de ensino deveriam ser responsáveis por essa capacitação (formação continuada) devido aos problemas que os professores enfrentam durante a sua docência, apontados no questionário, como a falta de tempo, o trabalho burocrático, ausência de ferramentas acessíveis e a escassez de interação entre a instituição e professor. Percebe-se também, ainda no questionário, a falta de 
compreensão da instituição quando se refere às necessidades dos docentes, pois esse é mais um fator relevante que a instituição deveria abraçar:

\begin{abstract}
por isso, faz-se necessário a reflexão da prática orientada por perspectivas teóricas que possibilitem questionar a própria prática e dar origem a novas necessidades para o aperfeiçoamento do trabalho profissional. As novas exigências do século XXI que vêm sendo traduzidas nas reformas do sistema educativo impõem rupturas profundas no agir profissional do professor que, consequentemente, exige novas necessidades formativas (NUÑEZ; RAMALHO, 2002, p. 04).
\end{abstract}

Em razão disso, identificamos que a instituição e os docentes precisam estar em constante harmonia, para que um ajude ao outro no caminhar dos aportes teóricos necessários, no sentido de garantir uma educação de qualidade para os alunos. A experiência na elaboração deste trabalho permitiu isso, a partir dos nossos erros e acertos foram construindo uma base de pesquisas e questionamentos sobre a formação docente.

\title{
CONSIDERAÇÕES FINAIS
}

O novo ensino médio vem sendo articulado há mais de uma década, com o objetivo de educar para uma nova sociedade e uma nova geração. Os dados obtidos pela presente pesquisa evidenciam que há, ainda, a necessidade da garantia de formação continuada e compromisso para com o professor por parte das políticas públicas e de construção de uma nova identidade escolar, que deve ressaltar seu novo formato de ensino que visa a união entre os objetos de conhecimento e instituição e aluno.

O PROESDE tem sido uma ótima oportunidade para ampliar nosso conhecimento e com este artigo não foi diferente, todos os tutores e referências que tivemos contato foram essenciais para que pudéssemos chegar em um produto final, encerramos este artigo com a sensação de dever cumprido.

Os debates e reflexões dos dados obtidos centraram-se na importância de levar o conhecimento e discussões produzidas e fomentadas na universidade para as instituições escolares, para que haja troca de conhecimento e continuidade de aprendizagem, tanto por parte dos professores quanto dos acadêmicos. Ressalta-se aqui o privilégio de fazer parte do PROESDE, que durante todo o percurso formativo incentivou a produção de conhecimento e colocou os bolsistas como protagonistas da aprendizagem, possibilitando trocas entre professores, acadêmicos e instituições 
escolares.

As dificuldades que permearam nosso trabalho foram a falta de interesse durante o trabalho em equipe do artigo como também, nos professores que optaram por não responder nosso questionário da pesquisa.

\section{REFERÊNCIAS}

BRASIL, BNCC. Base Nacional Curricular Comum Curricular. Ministério da Educação, Brasília, 2019.

BRASIL. Como elaborar o plano de desenvolvimento da escola. $1^{1}$ ed. Brasília. Disponível em: <http://portal.mec.gov.br/component/content/article/137-programas-eacoes-1921564125/pde-plano-de-desenvolvimento-da-educacao-102000926/176apresentacao>

MACEDO, Neusa Dias de. Iniciação à pesquisa bibliográfica. São Paulo: Edições Loyola, 1995.

MOLL, Jaqueline. O PNE e a educação integral: Desafios da escola de tempo completo e formação integral. Retratos da escola, Brasília, v. 8, n 15, 369-381, jul/dez. 2014. Disponível em: <http://retratosdaescola.emnuvens.com.br/rde/article/view/447/578> Acesso em: 18 jan. 2021.

NUÑEZ, Isauro Beltrán; RAMALHO, Betânia Leite. Estudo da determinação das necessidades de professores: o caso do novo ensino médio no Brasil-elemento norteador do processo formativo (inicial/continuado). Revista Iberoamericana de Educación, v. 29, n. 1, p. 1-18, 2002

SANTA CATARINA. Secretaria de Estado da Educação. Currículo Base da Educação Infantil e do Ensino Fundamental do Território Catarinense. Florianópolis: SED, 2019.

SANTA CATARINA. Governo do Estado. Secretaria de Estado da Educação. Proposta Curricular de Santa Catarina: formação integral na educação básica. Estado de Santa Catarina, 2014.

SANTA CATARINA. Secretaria de Estado da Educação. Caderno de orientações para a implementação do novo ensino médio. Florianópolis: Editora Secco, 2019.

SHIROMA, Eneida Oto. MICHELS, Maria Helena. EVANGELISTA, Olinda. GARCIA, Rosalba Maria Cardoso. A tragédia docente e suas faces. In: EVANGELISTA, Olinda. SEKI, Allan Kenji (org.). Formação de professores no Brasil: Leituras a contrapelo. 1 ed. Araraquara - SP: Junqueira\&Marin, 2017.

VASCONCELLOS-GUEDES, LILIANA; GUEDES, L. F. E-surveys: Vantagens e limitações dos questionários eletrônicos via internet no contexto da pesquisa científica. X SemeAd-Seminário em Administração FEA/USP (São Paulo, Brasil), 
p. 84, 2007.

TRUJILLO FERRARI, A. Metodologia da pesquisa científica. São Paulo: McGrawHill do brasil, 1982. 